\title{
Putting strategy into action - The role of artefacts for business
}

\section{format replication}

\author{
Martin Friesl \\ Lancaster University Management School \\ Joanne Larty \\ Lancaster University Management School \\ Claus Jacobs \\ University of Bern
}

\begin{abstract}
In order to facilitate the implementation of replication strategies, organizations often use a variety of artefacts such as manuals and handbooks. Existing research has largely focused on the extent to which artefacts can act as knowledge repositories that help to facilitate replication. This body of literature has made significant contributions to our understanding of the role of replication, but has focused more on highlighting key challenges involved in the codification of knowledge. This paper demonstrates that artefact based replication is a double edged sword. While replication is enabled by, 'configuring' artefact-action relationships (focussing, situating, coordinating) our analysis also reveals that replication is constrained by 'decoupling' artefact-action relationships (accounting, differentiating, disengaging). Our findings contribute to research on replication and provide a more nuanced understanding of why the implementation of replication strategies might fail. We also add to the recent debate on socio-materiality in strategy research more generally.
\end{abstract}




\section{Introduction}

Strategies of multi-unit firms are often built around a set of valuable routines that underpin the business format of the organization (Amit \& Schoemaker, 1993; Eisenhardt \& Santos, 2002). In such cases, strategy implementation includes replicating those routines across dispersed units (Argote \& Ingram, 2000; Helfat \& Peteraf, 2003; Nelson \& Winter, 1982). This is often called a replication strategy (Winter \& Szulanski, 2001). Examples include IKEAs approach to internationalization (Jonsson \& Foss, 2011), Intel's production of computer chips (McDonald, 1998) or the growth strategies of large franchise organizations (Winter \& Szulanski, 2001; Winter et al., 2012). In order to facilitate the implementation of replication strategies, organizations often codify information about routines in a range of artefacts such as manuals, handbooks or standard operating procedures. These artefacts are intended to guide, facilitate and coordinate the replication of routines across organizational units (Baden-Fuller \& Winter, 2005; D'Adderio, 2001; D'Adderio, 2003; Zander \& Kogut, 1995; Zollo \& Winter, 2002).

Existing research has questioned the efficacy of artefact based replication. This is due to the difficulties of codifying contextually embedded, causally ambiguous and partly tacit knowledge (Baden-Fuller \& Winter, 2005; King \& Zeithaml, 2001; Nonaka \& Takeuchi, 1995; Szulanski, 1996; Winter \& Szulanski, 2001). Yet, the focus of many studies has remained on the characteristics of artefacts as 'knowledge repositories', rather than the actual use of those artefacts in practice. This is an important difference. While prior research emphasises the important role of observable working examples of organizational units, which serve to demonstrate everyday practices including the use of artefacts (Jensen \& Szulanski, 2007; Nelson \& Winter, 1982; Szulanski \& Jensen, 2004; Winter \& Szulanski, 2001; Zenger \& Lazzarini, 2004), an explicit focus on how actors use artefacts in practice has largely remained a "black box" (D'Adderio, 2008; Güttel et al., 2012). The purpose of this paper is to 
unpack this "black box" by using a practice perspective to explore how the use of artefacts impacts on the implementation of a replication strategy.

For practice theorists, artefacts are central to everyday activities, practices and routines (Giddens, 1984; Knorr-Cetina, 2001; Orlikowski, 2007; Pentland \& Feldman, 2005; Reckwitz, 2002). This implies that the implementation of replication strategies is inherently material, shaped by the artefacts actors use. By drawing on practice theory, this paper argues that research on replication would benefit from investigating how the use of artefacts in replication practice influences the implementation of replication strategies. Practice theory provides an avenue to explore the ways in which the use of artefacts enables or constrains actions at the unit level and thus helps to provide new insights into how these actions might impact on the overall strategy of the organization. This paper uses the term artefact-action relationship to denote how individual actions are inherently shaped by the situated use of artefacts. Based on this theoretical understanding the paper addresses the following research question: How does the use of artefacts shape the implementation of a replication strategy?

In order to explore this research question this paper adopts an inductive, explorative case study design (Easterby-Smith et al., 2008; Suddaby, 2006). The research context of this study is the replication strategy of Alpha, a large franchise network. In particular, our analysis investigates the use of artefacts in the replication of Alpha's sales and marketing routines. The data illustrate how franchisees' use of artefacts in practice guides replication and facilitates local level learning that underpins their attempt to replicate Alpha's business format. Our analysis reveals two types of artefact-action relationships that influence the implementation of replication strategies. Configuring artefact-action relationships (focussing, situating, and coordinating) which enable replication and decoupling artefact-action relationships (accounting, differentiating and disengaging) which constrain replication. 
This paper makes several theoretical contributions. First, the paper adds to the prevalent debate on the efficacy of artefact based replication (Baden-Fuller \& Winter, 2005; Winter \& Szulanski, 2001; Zander \& Kogut, 1995; Zollo \& Winter, 2002) by unpacking how the use of artefacts enables or constrains the implementation of a replication strategy. Second, the paper also contributes to research on replication by arguing that artefact-action relationships play a key role in facilitating replication, beyond the extent to which those artefacts are representations of often tacit knowledge. Finally, the paper also contributes to the growing body of research on the role of artefacts in strategy implementation (Leonardi, 2015; Vaara \& Whittington, 2012).

\section{The role of artefacts for the implementation of replication strategies: State of research and theoretical background}

The role of artefact use in strategy work

Research on strategy-as-practice considers strategy an accomplishment rather than something organizations have (Jarzabkowski et al., 2007; Johnson et al., 2003; Whittington, 2006). This focus on the practice of strategy foregrounds the strategic relevance of the seemingly mundane (Johnson et al., 2003; Rouleau, 2005) and acknowledges that strategy making, be it the development or implementation of strategy, is inherently material (Heracleous \& Jacobs, 2011; Heracleous \& Jacobs, 2008; Jarzabkowski et al., 2013; Vaara \& Whittington, 2012). Indeed, the study of the materiality of strategy making has become an important stream of strategy-as-practice research. Strategy making is carried out with a range of artefacts such as PowerPoint charts (Kaplan, 2011), frameworks (Werle \& Seidl, 2015) as well as maps or pictures (Jarzabkowski et al., 2013; Miettinen \& Virkkunen, 2005); and those artefacts matter (Dameron et al., 2015; Whittington, 2007). Jarzabkowski and Pinch (2013) even call materiality the new 'black' in strategy research. 
Interest on the role of materiality in strategy work has developed in parallel to a wider body of work on the role of artefacts in organization and management studies (Leonardi \& Barley, 2010; Orlikowski \& Scott, 2008). Strategy-as-practice research has embraced this tradition, by shedding light on how artefacts influence the development of strategy. A number of studies investigate how artefacts create shared meaning across groups (Spee \& Jarzabkowski, 2009) or how shared meanings are created in strategy workshops (Paroutis et al., 2015). Other studies investigate how strategy development, conceived of as a process of idea exploration, is mediated by artefacts. For instance, these studies show how the use of artefacts is negotiated (Belmondo \& Sargis-Roussel, 2015), how artefacts are made sense of (Heracleous \& Jacobs, 2008) or how artefacts affect participation in strategy making (Whittington, 2015). Other studies trace how different types of artefacts shape strategy development over time (Kaplan, 2011; Werle \& Seidl, 2015). The multifaceted nature of the use of artefacts in strategy making is also mirrored in the diversity of theoretical perspectives used such as a discursive lens (Kaplan, 2011), epistemic objects (Werle \& Seidl, 2015), affordances (Demir, 2015), or boundary objects (Spee \& Jarzabkowski, 2009).

While the role of artefacts in strategy development has received substantial research attention, research on how artefacts influence the implementation of strategy has remained scarce (Leonardi, 2015). This is mirrored by a lack of research on strategy implementation more generally. Indeed, in their review of strategy-as-practice research, Vaara and Whittington (2012) only highlight a handful of examples of strategy-as-practice studies explicitly addressing strategy implementation (Angwin et al., 2009; Balogun \& Johnson, 2004; Balogun \& Johnson, 2005; Fauré \& Rouleau, 2011). This paper addresses this gap by focussing on the use of artefacts for the implementation of a particular type of strategy: business format replication. 


\section{Challenges of replication strategies}

Previous research shows that replication strategies are an important form of value creation which facilitate growth and international expansion (Frery, 2006; Helfat \& Peteraf, 2003; Jonsson \& Foss, 2011; Szulanski \& Jensen, 2008), flexibility (Wirtz et al., 2007) and cost efficiency (Lervik et al., 2005). Replication strategies refer to the deliberate attempt of organizations to benefit from the valuable properties of existing routines (Jensen \& Szulanski, 2007; Winter \& Szulanski, 2001) by replicating, or 'copying' (Szulanski \& Jensen, 2008) them in new contexts, such as subsidiaries or across a network of franchise outlets (Helfat \& Peteraf, 2003; Winter, 1995; Winter \& Szulanski, 2001). The existing body of research points to three main challenges of implementing replication strategies which are labelled in this paper as: processual, contextual and relational challenges.

Processual challenge: Creating similar routines across multiple locations can often be challenging as the underlying processes that make up those routines, which includes the actions required to carry out those processes, need to be documented and described so that disparate units are able to carry out those tasks in a similar way. In other words, the challenge for replicating organizations is that they need actors to carry out similar processes across temporally and spatially separated units (Nelson \& Winter, 1982; Winter \& Szulanski, 2001). This is labelled the 'processual' challenge in this paper. Artefacts such as manuals, documented standard operating procedures or software tools are often central to providing representations of key processes in the form of flowcharts or checklists (Baden-Fuller \& Winter, 2005; Winter \& Szulanski, 2001; Zander \& Kogut, 1995) which are intended to facilitate "the coordination and implementation of complex activities" (Zollo \& Winter, 2002, 342). Szulanski and Jensen (2008) highlighted the importance of 'copy exactly' for international expansion and made a point of highlighting the importance of detailed processes and procedures. Examples also include Jonsson and Foss (2011) who showed how IKEA uses 
detailed descriptions of its store-designs as well as HR practices in order to ensure similarity across its retail outlets. Similarly, Intel's replication strategy depended heavily on artefacts with detailed processes and procedures to ensure that the quality of its manufacturing processes were replicated globally.

Contextual challenge: The implementation of replication strategies is also confronted by the 'contextual' challenge of embedding knowledge and routines in new contexts (Bamberger, 2008). The complexity of activities involved in the performance of organizational routines is a key hurdle for replication strategies (King \& Zeithaml, 2001; Szulanski, 1996). This also refers to the perceived ambiguity of units in how to implement and integrate these activities into a meaningful whole (Ambrosini \& Bowman, 2005; Lippmann \& Rumelt, 1982). Moreover, this ambiguity might be aggravated as handbooks, manuals and process descriptions are only abstractions of routines and are not only interpreted within different contexts and situations, but also need to be contextualized to specific regional implementations (Lervik et al., 2005; Reynaud, 2005). Contextualisation brings with it a multitude of challenges for replication as regional adaptations can have far reaching consequences on the replication of the business format (Szulanski \& Jensen, 2008).

Relational challenge: implementing replication strategies also involves what are termed here 'relational' challenges. These challenges refer to the relationship and interaction of headquarters and units that affects the extent to which routines are implemented (Davies et al., 2011). There is a difficult balance to be maintained in this relationship due to the tension between compliance and regional adaptation (Davies et al, 2011; Winter and Szulanski, 2001). This tension often gives way to differences in objectives and agendas that affect coordination between HQ and regional units (Carlile, 2002, 2004; Paswan \& Wittmann, 2009). This has been a longstanding debate in the context of replicator organizations such as 
franchise firms (e.g. El Akremi et al., 2011; Pizanti \& Lerner, 2003). This is of high relevance to the implementation of replication strategies.

These challenges are important in setting the scene for the focus of this paper. Rather than looking specifically into the challenges of codifying routines within artefacts (Baden-Fuller \& Winter, 2005), the paper turns attention to a practice perspective which focuses instead on how the use of these artefacts influences how replication unfold in practice; the paper focuses specifically on how the use of artefacts impacts on the three key challenges of replication. As such, a practice perspective offers a way of extending our understanding of the role of artefacts for the implementation of replication strategies. An important premise of practice theory is that actions and interactions are always mediated and shaped by artefacts (e.g. Bechky, 2003; Carlile, 2002; Carlile, 2004; Giddens, 1984; Pentland \& Feldman, 2005). In other words, the implementation of replication strategies is always enabled but potentially also constrained by the use of artefacts in practice. Based on this theoretical understanding, and from a practice perspective which focuses attention onto the use of artefacts, the paper addresses the following research question: How does the use of artefacts shape the implementation of a replication strategy?

\section{Methodology}

\section{Choice of method}

As the role of artefacts for the implementation of replication strategies has only received limited research attention, the study follows an explorative, single case study research design (Easterby-Smith et al., 2008; Yin, 2009). Single case designs have been widely used in prior research on replication (e.g. Güttel et al., 2012; Szulanski \& Jensen, 2004). Rather than aiming to achieve generalizability across a particular empirical context, single case designs are particularly useful for addressing "why" and "how" questions in organization and strategy research due to the in-depth insights into a particular research phenomenon (Easterby-Smith 
et al., 2008; Williams, 2000). As the paper is seeking to explore how the use of artefacts enables or constrains the implementation of a replication strategy, it is important that the research examines actors' use of artefacts in their replication practice (at the level of organizational units). Moreover, it is also important to investigate HQ's views of the role of artefacts and how they believe they support replication. Finally, while the paper is explorative in nature it follows an abductive approach (Ketokivi \& Mantere, 2010) by using the challenges of artefact-based replication as guiding concepts for our analysis.

\section{Empirical setting}

The paper uses franchising as a research context. Prior research already shows that the implementation of replication strategies in these organizations is traditionally supported by a variety of artefacts that are intended to facilitate the replication of the business format (Baden-Fuller \& Winter, 2005; Winter \& Szulanski, 2001). Franchising companies are based on a standardized business format that includes a portfolio of products and services as well as a set of organizational routines that are usually codified in manuals and handbooks. Based on these considerations Alpha is chosen as the research context for this paper. Alpha has been established as a franchise organization for over 20 years. It is headquartered in the UK with 56 franchise outlets in the UK, Ireland and continental Europe and focuses on promotional and education services. Alpha uses a large portfolio of artefacts to support its replication strategy. These include codified routines in the form of manuals, training presentations and videos, newsletters, letter templates, as well as software and databases.

In addition to the product portfolio, franchisees are required to closely follow Alpha's sales and marketing routines. HQ considers those routines as the primary driver to grow profitable regional outlets. It is essential for consistency across the organization that this growth evolves from the standardised implementation of organizational routines across outlets. Although other large, multi-national franchise brands have the luxury of a well- 
known, international brand to help drive sales, in most franchise organizations franchisees have to more actively seek sales and market their products or services, which is the case in Alpha. In organizations such as Alpha, sales, and in many cases marketing at the regional level, are the responsibility of franchisees. The implementation of tried and tested sales and marketing routines are thus often the key value drivers of the business. In addition, similar to many other franchise organizations (Blair and Lafontaine, 2005; Doherty, 2007), in order to support the implementation of routines, Alpha relies heavily on a series of artefacts that includes operations manuals and other supporting documents. Alpha thus represents a typical franchise organization and an ideal empirical case setting to investigate the role of artefacts in the implementation of replication strategies.

\section{Artefacts and replication in Alpha}

Alpha's replication strategy is about creating profitable regional sales outlets. The routines for sales and marketing are thus considered to be the main value drivers of the business and Alpha has a portfolio of artefacts to support local level replication. The implementation of these routines involves the use of a multitude of artefacts. Figure 1 below illustrates the wide range of artefacts involved in the replication of the Alpha business. An artefact that is central to Alpha's business is the 'Ten Commandments' (the CEO considers this as the 'ten steps to sales success'). Artefacts such as the sales manual contain more detailed descriptions of each item from the 'Ten Commandments', including check lists and flow charts. Artefacts such as the quarterly franchisee newsletter, case studies of sales successes and training presentations are also provided as additional support, outlining what the CEO refers to as 'best practice'.

\section{INSERT FIGURE 1 ABOUT HERE}


Given the primary importance of franchisees proactively seeking new sales opportunities to develop a sustainable customer base, the paper focuses on how franchisees' use of sales and marketing artefacts supports Alpha's replication strategy.

\section{Data gathering}

In order to understand how franchisees' use of artefacts influences the replication of sales and marketing routines, our study draws upon a wide range of data sources. First, Alpha provided us access to all artefacts used by franchisees to replicate the sales and marketing routines. This included operating manuals, product manuals, industry factsheets, newsletters, case studies, letter templates, marketing materials, as well as product and service catalogues; it also included access to software and databases used by franchisees to target key customers. From this list, 15 artefacts were identified as supporting the marketing and sales processes (see Figure 1). Second, 20 semi-structured interviews were conducted with franchisees, including eight visits to franchisees' premises, to explore how those artefacts were used in practice. Franchisees were questioned about how they used the artefacts and on the visits they were asked to demonstrate how they used them; for all franchisees further questions were asked about how and when they used certain artefacts whilst conducting their daily business and the extent to which they helped them. These visits and interviews helped to understand the different ways in which artefacts were used and how these uses influenced local practices. In addition, interviewees were engaged in a conversation about their individual practice and challenges in setting up and running a franchise outlet. This provided further insight into franchisees' evaluation of the different artefacts in supporting the growth of their business. All interviews, except three, were recorded and transcribed verbatim. For all other interviews extensive notes were taken during the interview and written up immediately afterwards (McQueen \& Knussen, 2002; Yin, 2009). Third, eight interviews were conducted with the CEO and other HQ staff who were responsible for designing and maintaining artefacts, to 
find out more about the reasons for the development of those artefacts and how they believed they supported replication. Fourth, quarterly meetings were attended to observe how headquarters promoted the use of artefacts to franchisees. This helped to triangulate the findings from the interviews.

\section{Data analysis}

The analysis is based on four steps. Two authors were involved in data analysis. The third author played the role of devil's advocate. They critically questioned the analysis and provided ideas for further themes (Nemeth et al., 2001). The first step was to compile a list of all artefacts used by Alpha franchisees to support replication of the sales and marketing routines. The second stage of analysis involved compiling descriptive accounts of how artefacts were used at the local level to replicate Alpha's sales and marketing routines. This stage drew on visits to franchisees as well as interview data to explore the ways in which franchisees use, and describe the use and significance of, the different artefacts for supporting their practice of the sales and marketing routines.

In the third step the processual, contextual and relational challenges were used as a framework for organizing those descriptive accounts. It allowed us to further understand how franchisees' use of artefacts linked to the key challenges of replication. For example, when franchisees described how they used artefacts to help them plan out their daily and weekly activities, this was categorised under processual. If franchisees used artefacts to help them understand how to implement routines specific to their own region, this was categorised as contextual. This stage involved several iterations. If particular accounts related to two different categories, they were placed in both categories.

In the final step, Miles and Huberman's (1984) theme and categorization analysis was used to identify descriptive first-order themes of artefact use relating to each of the three challenges of replication. These emergent themes were refined through several iterations 
(Bartunek et al., 1996). We were also mindful that the themes needed to be representative across the sample of franchisees, rather than being specific to only one or two instances. From these first-order themes further categories were identified which differentiated between accounts which enabled and others which constrained replication. For instance, for accounts which had been categorised as contextual, the authors identified how some of those accounts related to how franchisees used artefacts to help situate their activities specific to their own regions, whereas other accounts demonstrated how franchisees used those artefacts to highlight regional variations that required deviations from the standardised routines; these were labelled "situating" and "differentiating" respectively. These labels were termed artefact-action relationships as they related to how franchisees' use of artefacts influenced their local activities. In total 6 artefact-action relationships were identified. Figure 2 provides an overview of the descriptive first order themes and second order categories as well as well as the representation of these second order categories across the sample.

\section{INSERT FIGURE 2 ABOUT HERE}

\section{Findings: Business format replication at Alpha}

The findings are illustrated through examples of artefact use in the context of Alpha's sales and marketing routines as these are not only central to the business, but also provide a focused context to illustrate the arguments. We use the umbrella term 'configuring' relationships to describe three distinct artefact-action relationships which enabled Alpha's replication strategy through overcoming the processual, contextual and relational challenges (see Figure 2); franchisees used artefacts to: focus on the necessary activities required to run a franchised outlet (overcoming the processual challenge); to facilitate the situating of 
activities within regional contexts (overcoming the contextual challenge); and to coordinate their activities to help align their goals with those of HQ (overcoming the relational challenge). At the same time, three artefact-action relationships were identified which constrained Alpha's replication strategy where franchisees used artefacts (referred to as decoupling relationships): to account for practice in order to signal compliance (adding to the processual challenge); to differentiate regional practices and making a case for regional variations (adding to the contextual challenge); and to justify disengaging from the relationship following non-personalised communications and the continual reiteration of what needs to be done and when (adding to the relational challenge).

\section{Configuring artefact-action relationships}

The use of artefacts in practice plays an important role in enabling the implementation of Alpha's replication strategy. Three artefact-actions relationships are identified which facilitate overcoming the processual, contextual and relational challenges of replication which are labelled: focussing, situating and coordinating relationships. These artefact-action relationships are described in more detail below.

Focussing on core activities. It is rare that franchisees joining Alpha have any prior experience in running a business. Setting up and running an Alpha franchise outlet is therefore a complex task that requires franchisees to perform a variety of different activities. These activities not only involve getting in place supporting administrative processes (such as book-keeping and accounting), but also carrying out activities to search for and sell to new customers, to be able to source suppliers, and to then deliver products on time and to specification. Artefacts such as the 'Ten Commandments', industry specific manuals as well as the sales and marketing manuals enable franchisees to configure what activities need to be carried out and when in order to run an Alpha business. Configuring can be illustrated 
through the way the use of these artefacts enable franchisees' to sequence local processes. For example, industry specific manuals " [...] talk about the marketplace [...] how you access it, where you go, what collateral you use" (CEO). The sales manual also provides check lists and flow charts, for instance the CEO told us about the check list for invoicing which is outlined in the sales manual and was also on one of the training videos:

"[...] you send out the invoice with the goods, don't send it out at the end of the month, send it out with the goods. At the end of 30 days you send a statement, at the end of the 37 days you make a phone call. At the end of 47 days you send a legal letter."

As such configuring is facilitated through a specific artefact-action relationship. For example, the sales and marketing manual is used by both new franchisees and those with more experience. For newer franchisees, the manual plays an important role as a reference point that provides essential information about the core activities of the business. Several interviewees emphasized how they had the manuals 'ready to hand'. As one franchisee stated, "when you come off the course it's open on your desk and you use it [everyday]". For more experienced franchisees, the manuals play an important role as an anchor from which they can realign their activities with the core aspects of the business format. For instance, Tom stated:

“...it's good to step back, look at the manual and just realign your objectives, like doing your marketing plan and making sure you're in constant contact with the clients or potential clients. [...]".

Similarly artefacts such as the 'calendar' help franchisees understand when activities should be carried out, as one franchisee explained:

"[...] the calendar has dates, for example Week One in January you send this out; Week Three you follow it up. It tells you what to do and it's got the targets for each time of the year"

These examples demonstrate the important role of configuring as an artefact-action relationship in supporting Alpha's replication strategy. This relationship enables replication through the temporal sequencing of activities. 
Situating activities in the local context. One of the important aspects of any franchise organization is that franchisees must be able to situate routines in their respective sales regions. This is particularly important as regions might substantially differ with regard to the mix of customer segments Alpha targets. Invariably franchisees need to be able to situate their activities in the context of their regions. The CEO recognises this challenge and told us about the need for franchisees to share 'best practice', which he defined as the situating of core activities within different sales regions. Artefacts such as the newsletter and case studies were indeed used by franchisees to share 'best practice' and to learn about how others have situated organizational routines in practice; in other words, there is an artefact-action relationship which enables franchisees to learn how to situate activities in practice.

For example, case studies provide information about how franchisees have performed particular aspects of the sales process. Franchisees indicated how they used these case studies to learn about the implementation of routines within their regions. For instance, Silvia, a franchisee, stated how case studies encouraged her to find out more about what particular franchisees had done:

"[in one case study] ...there was a guy in [city] and I wanted to know more about how he runs his business because I want to learn more from him."

In another example, Philip described his challenge to effectively implement routines in his region; in particular the degree of creativity required for the implementation of new marketing campaigns: "it can be a bit tricky because it takes time to think of different ideas". This is where he felt that the case studies helped to not only provide "some quite good ideas", but to also "help think more about my region and my customers and what they are looking for".

The situating artefact-action relationship is important in providing an avenue for learning different ways of performing routines in different sales regions. In addition to case studies, articles which appeared in the quarterly newsletters, training videos, as well as presentations 
at the quarterly meetings also played a key role in encouraging the sharing of ideas. The configuring and situating artefact-action relationships are complementary and together play an important role in enabling Alpha's replication strategy.

Coordinating activities across units. A key challenge for any franchise organization is to ensure the alignment of franchisees' and HQ's goals so that franchisees' activities are aligned to the future direction of the business. The coordinating artefact-action relationship enables this through artefacts facilitating how franchisees plan their future activities so that they are in line with the direction of HQ. Within Alpha, a number of artefacts facilitate the coordination of HQ and franchisee activities. As the CEO stated, on a monthly basis:

"we [i.e. HQ] continually outline "these are things you need to be doing next month" [...] [in addition] we send them a calendar [...] we send them a diary, we reiterate [in the presentations] "don't forget to do this next month."

In one quarterly meeting HQ staff placed considerable emphasis on one particular new product line which is referred to in this study as 'Fabrico'. HQ wanted franchisees to concentrate on Fabrico over the next 6 months. The importance of Fabrico was demonstrated through a presentation at the quarterly meeting, a new product factsheet, new case studies available on the intranet, plus a range of articles in the quarterly newsletter. The interviews with franchisees provided an insight into how such artefacts were used to enable the coordination of activities across regional outlets and help to align HQ's goals of increasing focus on the Fabrico product line. Franchisees emphasised the importance of Fabrico for their business. The coordinating artefact-action relationship plays an important role in working alongside the configuring and situating relationships, to support the replication strategy through highlighting the future direction of franchisees' businesses. 


\section{Decoupling artefact-action relationships}

Although artefact-action relationships enable replication they may also constrain the implementation of Alpha's replication strategy. Our findings point to how artefacts are used by franchisees to decouple their actions from the formal processes of the organization, in order to preserve control over actions at the regional level. We find that decoupling is manifest in three different artefact-action relationships. At the processual level, the use of the manual also allows franchisees to account for their activities while maintaining highly localized practices ('accounting relationship'). Similarly, relating to the contextualisation challenge, artefacts foreground specific regional or individual differences which franchisees use to make changes to regional practices, whilst complying with the formal structure of the organization ('differentiating relationship'). Finally, relating to the relational challenges of replication, the persistent use of artefacts, particularly in non-personalised ways, to control and monitor the actions of franchisees can also give rise to franchisees disengaging from the structure of the organization ( 'disengaging relationship').

Accounting for unit level activities. Franchisees use artefacts to account for unit level practice through 'ticking off' key activities and thus signalling compliance with reporting requirements. The data suggests that on occasion such reporting may have little resemblance to activities actually carried out at the local level. This is labelled the accounting artefactaction relationship. The accounting relationship refers to the process whereby franchisees separate accounts of their practices from their actual practices. Indeed, in initial interviews franchisees were keen to point out how they had completed the necessary actions for sales and marketing, demonstrating to the interviewer evidence of what they had done (as though the interviewer was there to judge their actions), but later franchisees either contradicted themselves (when they talked about their actual actions), or more openly discussed how their 
use of artefacts limited their actions. The accounting relationship can be illustrated by using franchisees' use of the 'Ten Commandments' as an example.

The 'Ten Commandments' clearly outline what activities need to be carried out and when and thus provides an important means through which franchisees are able to account for their activities. Franchisees' accounts of their practices echoed the steps listed on the 'Ten Commandments', presenting a tick-box approach to how they had carried out those activities. An extract from the interview with Tom provides a useful illustration. In the initial part of the interview Tom was asked about how he used artefacts for his weekly activities, his reply was echoed by other franchisees when asked about what activities they had been focusing on. Tom's reply mirrors the steps outlined in the 'Ten Commandments'.

"[...] at the beginning of each month we draft up a marketing plan and from that we'll do $x$ number of telephone calls, we'll send out $x$ number of awareness cards, we'll do cold calling, walkabouts and things like that [...]."

However, later in the same interview, Tom alluded to how in reality his activities deviate:

"we prefer to follow the model but do it on a sort of a more personable basis, based on our reputation with customer service"

Tom was also asked to explain what he meant by this statement, and after checking that "none of this goes back to $H Q$ ?" He mentioned that he rarely follows the activities listed in the various flow-charts included the sales and marketing handbooks.

Thus, this artefact-action relationship leads to franchisees' accounts of their actions becoming separated from regional performances of organizational routines. Given this disparity between what activities are accounted for and what activities actually happen, there is evidence to suggest that the replication of Alpha's business format is often unbalanced or incomplete.

Differentiating local activities. The use of artefacts may also constrain replication by foregrounding regional or individual differences which franchisees use to make changes to regional practices, whilst complying with the required practices of the organization. 
For example, Shirley, a franchisee, often referred to particular case studies or training videos to highlight how customers in her region have very different needs, one particular case study had stood out:
"[...] my customers are very different from his, because mine are in [county], they are short of time and they have a bit too much money, the pace is different. Here it's 'I want it now' 'I want it yesterday', e-mails are much shorter, you don't put 'Dear Shirley' at the beginning of the e-mail, you just go straight to the e-mail, plus my customers want a more quality product"

For Shirley, case studies such as this provided a way for her to focus on regional variations, particularly in what products she focused on and why she did not participate in particular marketing campaigns recommended by headquarters. It also provided a way for her to change her practices in how she used supporting artefacts such as sales letters and customer documentation. In another example, Philip explained to us how he is not 'hard sell' or 'ruthless' like other franchisees, and that he does not want to 'stalk' his clients through calling them on a regular basis as he perceived the sales manual, previous case studies, and the 'Ten Commandments' to describe. In other words, Philip used these artefacts to help him differentiate himself from other franchisees and thus build a case for a different set of local activities whilst also complying with the overarching requirements of the organization (i.e. for cold calling, marketing and sales).

The challenge for headquarters is that although artefacts can overcome the contextualisation challenge, those very same artefacts can lead to artefact-action relationships which add to the contextualisation challenge and thus constrain the replication strategy through providing a means through which franchisees are able to adjust regional practices based on regional and individual variations.

Disengaging with $H Q$. Above, the paper highlighted how the use of artefacts can help to coordinate the goals of HQ and franchisees. Yet, franchisees' use of artefacts may also dissuade them from aligning the goals of their regional outlet to that of the franchise HQ. The 
use of artefacts to coordinate the goals of HQ and franchisees, especially when such communications are persistent, non-personalised and aimed at increasing sales, can also evoke uncomfortable sentiments amongst franchisees about continually being reminded about what they should be focusing on leading to them disengaging from the goals of HQ. This is labelled a disengaging artefact-action relationship. For example, Mark, a franchisee, was becoming irritated by what he saw as pressure from HQ in that artefacts such as case studies, newsletters, industry fact sheets were all urging franchisees to run particular campaigns over the forthcoming period and for them to focus on increasing sales; the extent of these artefacts had led to increased levels of cynicism. Mark described one particular case study in the newsletter as 'propaganda':

"[...] to be honest the [case study in the] Newsletter is propaganda, really. If you're going to be cynical about it, it's basically [the CEO] telling you again what he's always told you, that you need to increase sales"

Similarly, other franchisees, such as Janet were also quite vocal about what she saw as the continual pressure from the diary and calendar of events which were sent to franchisees on a regular basis. She saw these as non-personalised 'reminders', rather than as a way of coordinating activities, surfacing a tension in the franchisee-HQ relationship:

"[...] I can't get them [headquarters] to not remind me [...] if I have done it I don't want to get reminded [...] it's quite annoying!"

David also believed that case studies of what could be achieved in future campaigns were only there to act as a 'showcase' of what the top performing franchisees could expect to achieve and in such a way they often highlighted the lack of sales performances elsewhere in the franchise network. He commented on the use of those artefacts:

“"is this useful for me?" To be honest, not really.[...] I'm really pleased for them [and what they are focusing on] but what does that mean to me? It's basically a cheerleading publication'

Thus, although artefacts can help to coordinate the goals of HQ and franchisees, their persistent use in non-personalised ways may lead to artefact-action relationships which cause 
franchisees to disengage from the goals of HQ, thus having a negative effect on Alpha's ability to implement its replication strategy. Attempting to overcome the relational challenge of franchise organizations is thus a double-edged sword. On the one hand, it requires a multitude of artefacts that support goal alignment, yet on the other, the artefacts that are designed to showcase the possibilities for future profit-making potential can lead to rebellion amongst franchisees, which manifests in disgruntlement towards the organization.

\section{Conceptual interpretation}

This paper provides an in-depth study of artefact-action relationships and their role for the implementation of replication strategies. Below we develop a conceptual model that juxtaposes three configuring artefact-action relationships that reduce the processual, contextual and relational challenges of replication, as well as three decoupling artefact-action relationships that maintain or even increase these challenges. Thus, the findings of this paper suggest that the use of artefacts creates a fine balance between enabling and constraining replication. While the study draws on data from a franchise network, it is argued that the findings are applicable to other contexts of replication and strategy implementation that involve artefacts such as handbooks, documentation or process visualizations. Figure 3 below illustrates the relationship between these conceptual mechanisms.

\section{INSERT FIGURE 3 ABOUT HERE}

Configuring artefact - action relationships: Configuring artefact-action relationships reduce challenges of replication by facilitating the creation of a focussed, situated and coordinated set of activities of activities in line with a firms' replication strategy. Implementing a replication strategy is a highly complex task for unit managers. This complexity results from the processual challenge of recreating a tightly coupled set of 
processes and routines. The focussing artefact - action relationship allows unit managers to deal with the processual change. The focussing relationship is defined as the artefact enabled patterning and temporal sequencing of activities across organizational units. In other words, the use of artefacts facilitates the coherent implementation of routines across dispersed organizational entities. It allows unit managers to account for local activities as being part of the business format and it helps them in temporally sequencing the routines and processes that make up the business format. The use of artefacts also enables actors to deal with the contextual challenge. Indeed, franchisees use artefacts as guidance in order to learn more about how to perform particular routines or target customers (situating relationship). This situating relationship is manifest in an artefact enabled learning process that allows franchisees to learn about regional nuances. Finally, the use of artefacts also addresses the relational challenge. This challenge is particularly evident in divergent interpretations of objectives at both the HQ and unit levels. The findings suggest that the coordinating artefactaction relationship may address this challenge. The coordinating relationship is defined as the timely reinforcement of Alpha's business format and the cross-unit orchestration of particular processes and routines (e.g. the role out of a new marketing campaign in all units for a particular segment). Thus, the coordinating relationship facilitates the temporary convergence of $\mathrm{HQ}$ and unit priorities.

Decoupling artefact-action relationships: While configuring artefact-action relationships reduces challenges of replication and thus enable the implementation of replication strategies, our findings also indicate that artefact-action relationships potentially maintain or increase replication challenges. Drawing on Meyer and Rowan (1977) we define decoupling artefact action relationships as the maintenance of a deliberate disconnect between actual practice and those described by the formal processes of the organization. In other words, franchisees use artefacts to maintain divergent regional practices. Our analysis revealed three decoupling 
artefact-action relationships (accounting, differentiating and disengaging) that affect the processual, contextual and relational challenges of replication.

The processual challenge of replication is about the re-creation of routines across dispersed units and manuals provide franchisees with the language to account for particular practices as described by the organizations (accounting relationship). Yet, while such descriptions provide the basis for franchisees to focus on activities they need to carry out, it potentially also creates a situation that provides an opportunity for decoupling. Franchisees are able to signal compliance with the business format yet their practices may deviate from the business format. Thus, the accounting relationship results in un-observed heterogeneity across units that might potentially result in cost and quality issues. Yet, decoupling artefactaction relationships not only affect the accounting of compliance they also provide the basis for the creation of divergent practice through contextual and relational challenges of replication.

The contextual challenge of replication requires replicatees to be sensitive to localization pressures in alignment with HQ. While the use of artefacts does facilitate such situating, our findings also suggest potentially negative consequences. We use the term differentiating artefact-action relationship to describe how franchisees use artefacts to foreground specific regional or individual differences that enable them to develop idiosyncratic, local solutions that deviate from Alpha's business format, whilst being legitimised through those same artefacts and thus complying with the formal processes of the organization. Finally, the findings also indicate that decoupling artefact-relationships also negatively affect the relational challenge of replication. This is labelled the disengaging artefact-action relationship. The findings suggest that the persistent, non-personalised reiteration of the same messages through artefacts may lead to frustration amongst franchisees and disengagement with the goals of HQ. Indeed, the Alpha case also indicates that artefacts become symbols for 
hierarchy and status within the organization which triggered cynicism and resistance among franchisees.

The artefact-action relationships identified in this study have important implications for the implementation of replication strategies. Managers use a variety of artefacts on a daily basis. These artefacts might even be designed with the dedicated purpose of facilitating the transfer of knowledge and helping to configure and to coordinate activities. Yet, our findings indicate that the material conditions created to facilitate replication might have emergent, unintended consequences that reinforce the challenges of replication. This is evident in the decoupling artefact-action relationships. Still, there is an important boundary condition to this study. This study focuses on artefacts that include textual documents as well as visual representations of processes and routines, such as charts or videos. While such artefacts are widely used for the purpose of replication, strategy implementation in other contexts might be strongly influenced by digital media as shown in a recent study by Demir (2015) or a variety of other artefacts which give rise to a different set of artefact-action relationships.

\section{Discussion}

Based on the findings presented above a number of theoretical contributions are made to three areas of literature. While this study mainly speaks to the literature on replication strategies, the paper also provides insights for the extant debate on strategy implementation as well as the growing discussion on socio-material practices in the strategy-as-as-practice field.

A practice perspective to artefact use does not consider artefacts as representations of knowledge but more fundamentally acknowledges that human actions and interactions are mediated and shaped by the things people use. Existing research argues that the embeddedness of organizational routines and the tacitness (Collins, 2001; Nightingale, 1998; Nonaka \& Takeuchi, 1995; Polanyi, 1964) of knowledge renders artefact based approaches to replication difficult (Nelson \& Winter, 1982; Szulanski, 1996; Winter \& Szulanski, 2001; 
Zander \& Kogut, 1995). Thus, extant research on replication benefits from insights into the mechanisms through which artefacts enable but potentially also constrain the coordinated implementation of routines across outlets. Based on a practice perspective, our findings provide a more nuanced view. This study shows that actors draw on a whole variety of textual and visual artefacts in order to perform particular tasks. But also, rather than transferring knowledge this study suggest that configuring, situating and coordinating artefact - action relationships results in the enactment of routines through the creation of locally embedded knowledge (Feldman \& Pentland, 2003; Pentland, 2003). The configuring artefactaction relationship reduces the complexity faced by replicatees both regarding the portfolio of activities that need to be performed, as well as their temporal sequence. At the same time artefacts have an 'epistemic' quality, as suggested by Knorr-Cetina (2001). This means, through their use they become triggers of practical learning by which replicatees acquire the processual and situated knowledge required to perform routines in practice. This also confirms recent findings of Güttel et al. (2012) who show the role of rule books for innovation in replicator organizations. Finally, artefacts become coordinating devices through which the performance of organizational routines across organizational units is reinforced.

The debate in extant research regarding the efficacy of artefacts for replication is also evident in our findings, but for very different reasons. Research on replication predominantly focuses on artefacts, such as handbooks and manuals as repositories of knowledge (BadenFuller \& Winter, 2005; Winter \& Szulanski, 2001; Zander \& Kogut, 1995; Zollo \& Winter, 2002). Thus, the inability of artefacts to convey the tacit knowledge necessary to perform routines has been highlighted as an important obstacle to replication (Szulanski et al., 2016). This paper goes beyond the ability of the artefact to capture tacit knowledge and instead investigates the relationship between artefact and action in practice. This allows us to identify a number of ways the use of artefacts can constrain replication. Indeed, our findings suggest 
that artefact-based replication might result in 'decoupling' underpinned by three artefactaction relationships (accounting, differentiation and disengaging). These artefact-action relationships also provide more nuanced insights into the materiality of resistance in replicator organizations (Szulanski, 2000) and provide new insights into the potential reasons for the failure of replication strategies.

On a more general level, the practice perspective provides researchers with a way of reconceptualising the notion of artefacts in research on replication (Friesl \& Larty, 2013). Extant replication theory focuses on the ability of artefacts to convey tacit and embedded knowledge (Zander \& Kogut, 1995). Shifting the perspective away from the extent to which artefact represents organizational knowledge, to how actors actually use artefacts, provides a more complex picture of the role of artefacts. Rather than limiting artefacts to the dichotomy of explicit versus implicit knowledge, this paper argues that it is through the use of artefacts in practice in which different artefact-action relationships give rise to actions which enable or constrain replication. Thus, on the one hand, this perspective explicitly conceptualizes artefacts as an integral part of actors' everyday activities through which the implementation of replication strategies unfolds.

Finally, while focussing on the specific context of business format replication, this paper also answers to a call in strategy research to investigate the role of tools and artefacts in strategy implementation more widely (Leonardi, 2015; Vaara \& Whittington, 2012). Previous strategy-as-practice research provides deep insights into how actors use artefacts and tools in the strategy process (Buergi et al., 2005; Spee \& Jarzabkowski, 2011). In fact, the use of artefacts for strategic activities in organizations has been identified as one of the central themes in strategy-as-practice research (Golsorkhi et al., 2011). While previous research has predominantly focused on the strategy process (Kaplan, 2011; Spee \& Jarzabkowski, 2011), less is known about the use of artefacts in strategy implementation. The paper provides 
insights into how replication, as a particular context of strategy implementation (Helfat \& Peteraf, 2003; Winter \& Szulanski, 2001), is influenced by actors' use of artefacts in practice. Artefacts, such as a franchise manual or software tools, are manifestations of strategy deliberation; they are representations of the intended strategy of a firm (Mintzberg, 2000). However, by highlighting that the use of artefacts in practice both enables the reproduction of practice and thus the realization of intended strategy, but also local adaptation and learning, the findings shed light on the reasons for the divergence of intended and realized strategy (Balogun \& Johnson, 2005).

\section{Conclusion}

This paper contributes to research on replication strategies by analysing how the use of artefacts enables but also constrains the implementation of replication strategies. The six artefact-action relationships identified in this paper provide several starting points for future research. By drawing on a multiple-case design, future research could contrast the role of artefacts in different industries or organizational settings. Future research could also identify contingency factors that help to explain under which conditions the use of artefacts enables or constrains replication. This might also involve research into the creation of handbooks for the purpose of replication. In line with existing work on the creation of artefacts, this potentially provides the opportunity to further understand the role of power and politics in replication strategies. Moreover, artefact-action relationships as well as the challenges of replication could be captured in the firm of item batteries as part of a survey research design. This would provide the opportunity to study artefact-based replication across a broader sample of replicator organizations.

While the findings of this paper contribute to the vibrant debate on artefacts and materiality in the strategy and organization literature, they have also implications for practitioners. Manuals, handbooks and newsletters etc. are taken for granted ways of 
conveying information. Yet, how these artefacts are actually used is usually not questioned. By differentiating between configuring as well as decoupling artefact - action relationships, this paper helps practitioners to become more mindful about the role of artefacts in the process of replication. 


\section{TABLES AND FIGURES}

Figure 1 Artefacts supporting the core processes in an Alpha franchised outlet

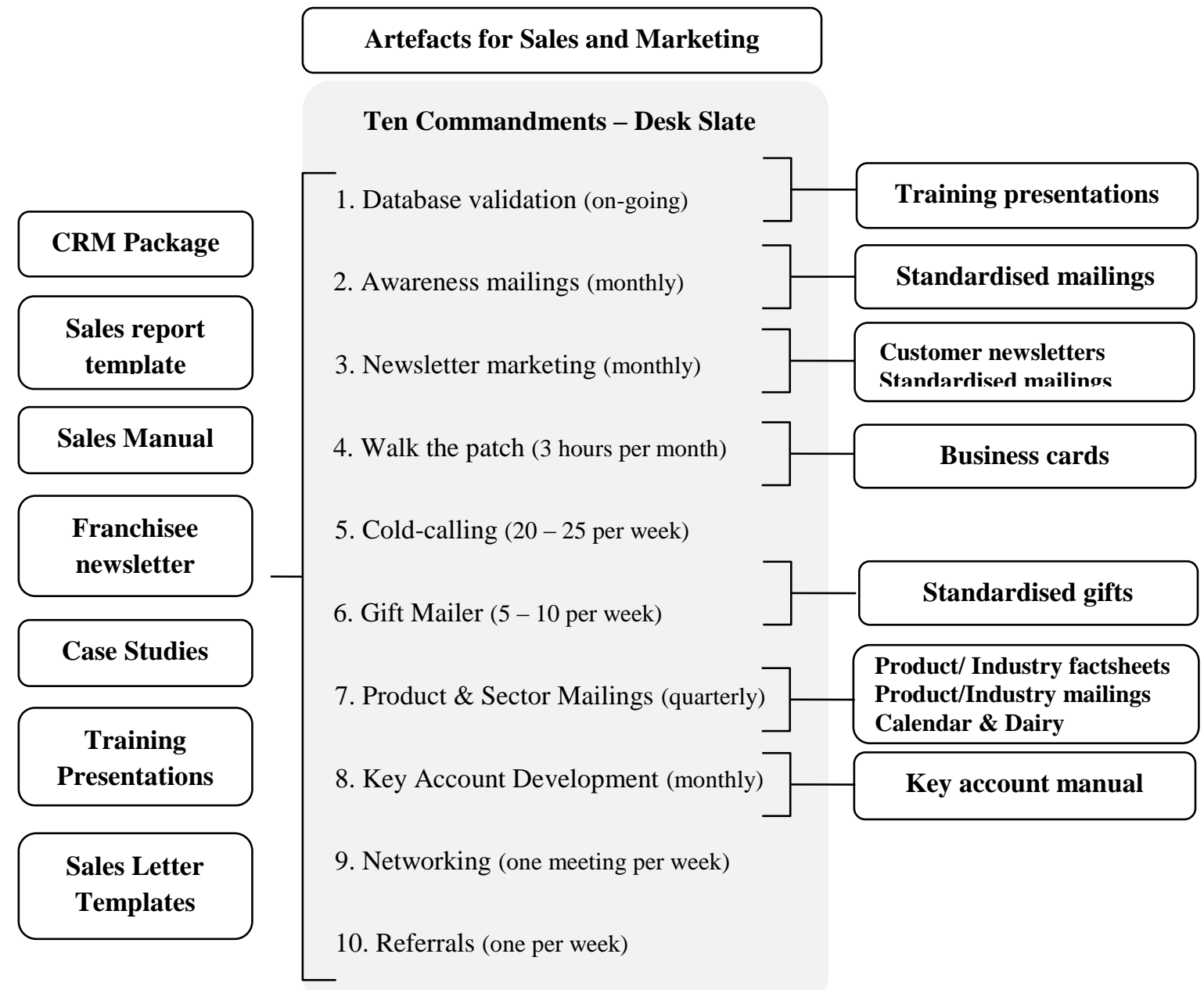

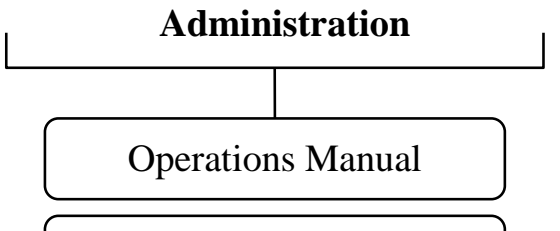

Sage Accounting Package

Sales League Table

Invoice Template

Business Stationery

Training Videos

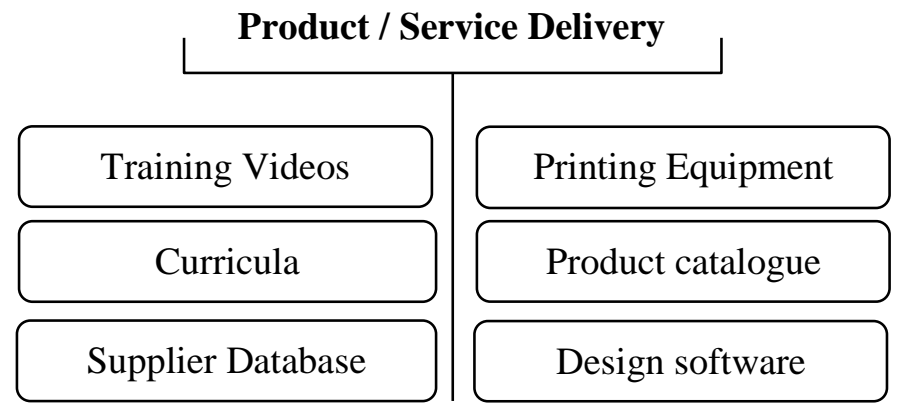

Supplier Database
Design software 
Figure 2 First-order description, second-order categories and aggregate dimensions

First-order description

Ten Commandments: franchisees use it to set out high-level overview of the key tasks underpinning their regional business

Calendar: franchisees use it to inform themselves about key industry-related events at different times of the year to understand what they need to focus on

Sales manual: used by franchisees to understand in more detail the flow of activities underpinning the key sales and marketing tasks

Sales manual: used by franchisees to understand what tasks need to be completed, and the suggested timescales that those tasks should be carried out during the sales

Case studies: used by franchisees to_understand successful implementations of

Alpha's processes and regional variations in customer requirements

Articles in newsletters: used by franchisees to illustrate examples of best practice implementations of Alpha's processes and key tasks

Training videos: used by franchisees to provide examples of regional best practice demonstrated by franchisees

Presentations at quarterly meetings: used by franchisees to understand regional challenges faced by other franchisees and encourage the sharing of ideas in order to find solutions to those challenges

Diaries: used by franchisees to indicate important areas of the business they should be focusing on during the forthcoming periods

Newsletter articles: used by franchisees to identify upcoming campaigns

Presentations at quarterly meetings: used by franchisees to highlight changes to, or the introduction of new, products / services and helps franchisees introduce this into their business planning

Case studies: used by franchisees to schedule new or updated products / services in their regions
Second-order categories

Aggregate dimension 
Figure 2 (continued)

First-order description

Sales manual: used by franchisees to understand what HQ believed to be the key tasks

Ten Commandments: used by franchisees to understand items to report on

Quarterly presentation: used by franchisees to highlight expectations of HQ on what the key tasks were for the following period and what they would be expected to report on

Newsletter articles: used by franchisees to understand what activities are deemed important by HQ Calendar of events: used by franchisees as a list for their next monthly report to HQ

Case studies: used by franchisees to highlight regional differences between franchisees and the need for different practices across regions, whilst maintaining compliance

Newsletter articles: used by franchisees to highlight differences between regional customers and how they can change their own practices whilst complying with organizational requirements

Case studies: used by franchisees to identify specificities of regions and to highlight practice differences which comply with the overarching organizational processes

Quarterly meeting presentations: used by franchisees to identify best practice ideas specific to particular regions, indicating viable regional variations

Newsletter articles: used by franchisees to highlight the non-personalised nature of

communications which creates frustration and reduces motivation for engaging with $\mathrm{HQ}$

Diary of events: used by franchisees to highlight the persistence of HQ communications and

requested activities, leading to further frustration

Quarterly meeting presentations: used by franchisees as a way of highlighting persistent messages

about the need to increase sales, leading to disenchantment with $\mathrm{HQ}$

Case studies: used by franchisees as benchmarking tools which indicate poor sales performance,

leading to disenchantment with the franchise organization
Second-order categories

Aggregate dimension

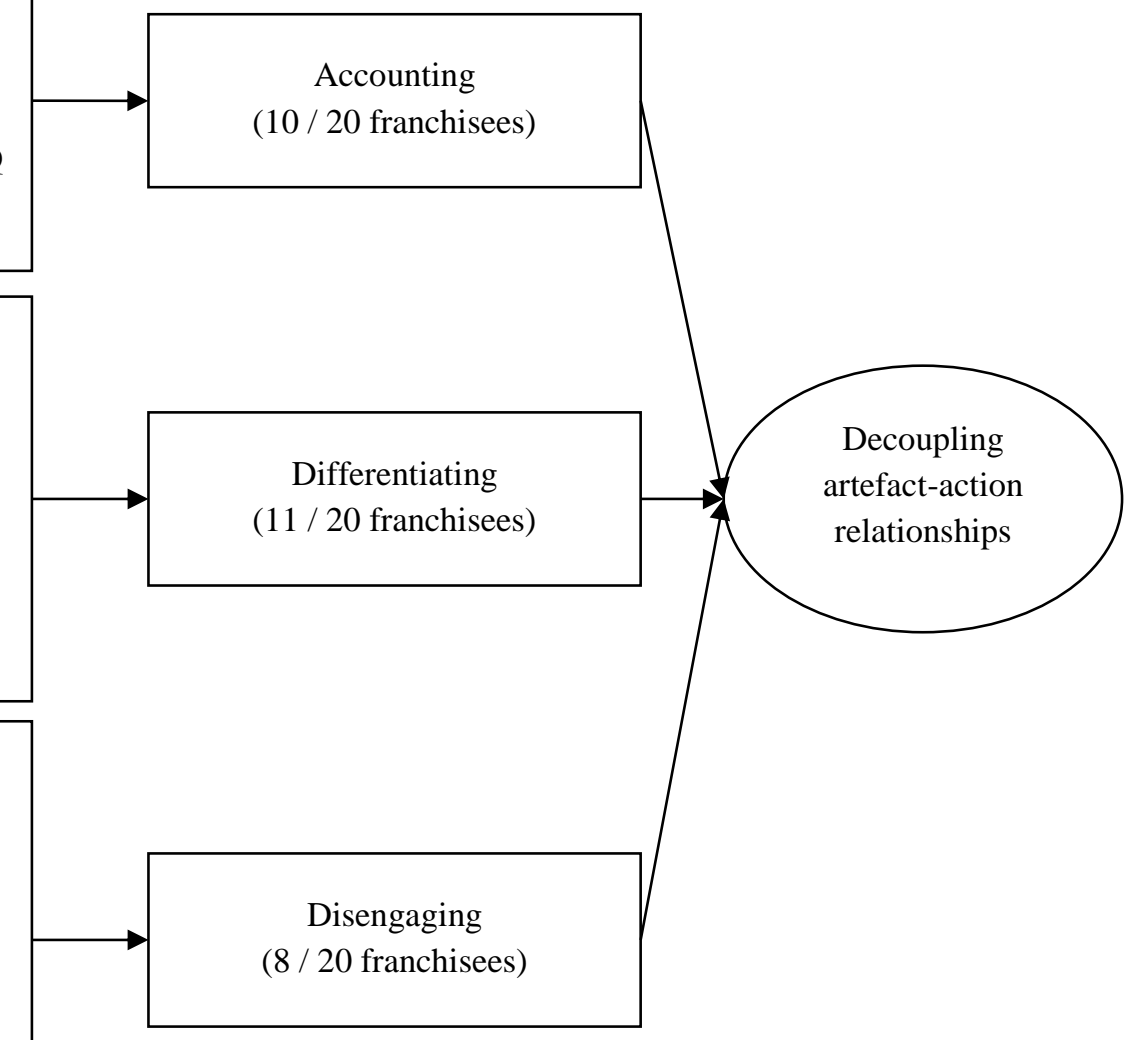


Figure 3 Configuring and decoupling artefact-action relationships

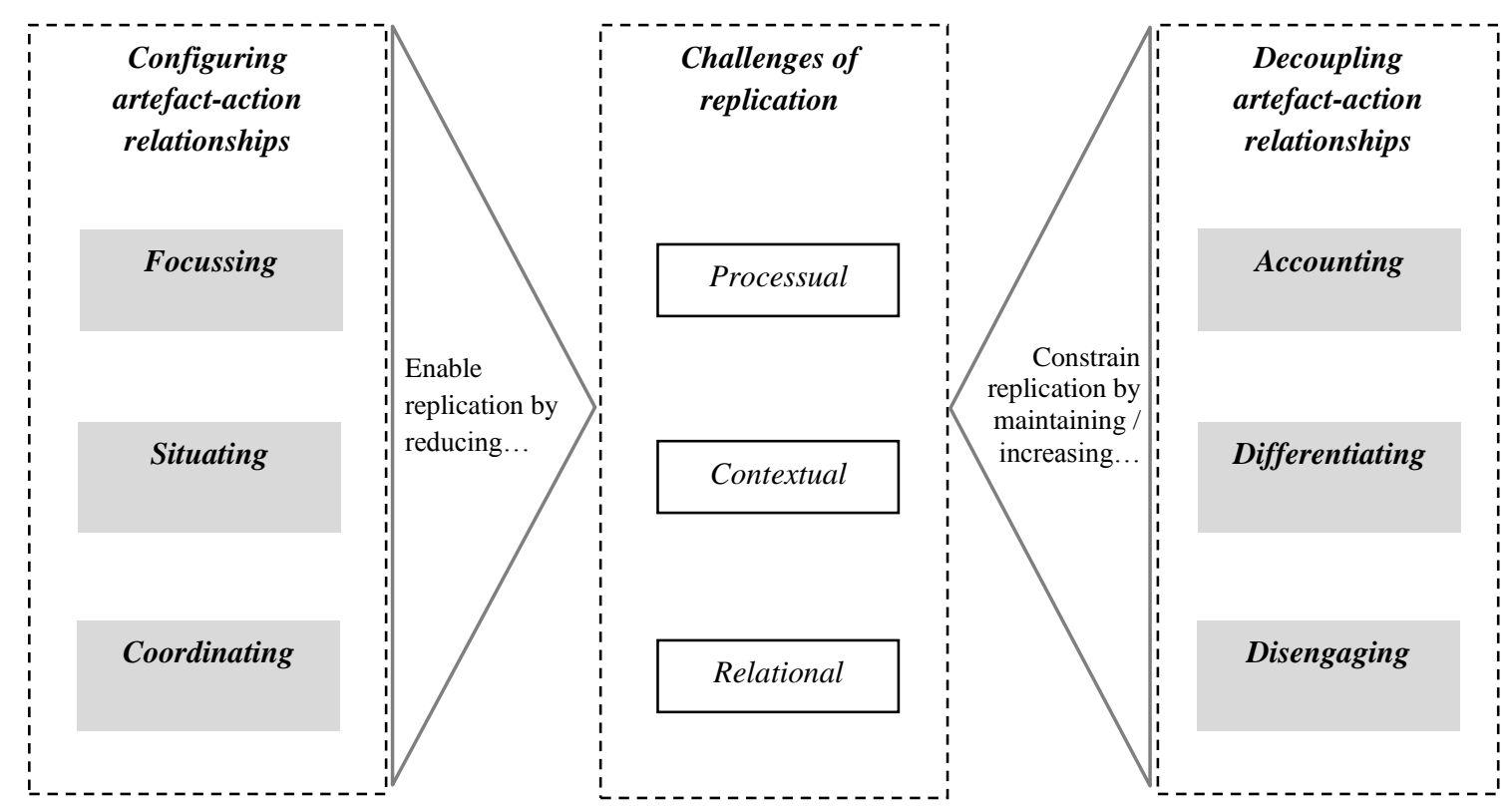




\section{References}

Ambrosini, V. and C. Bowman, 2005, "Reducing causal ambiguity to facilitate strategic learning". Management Learning, 36: 493-512.

Amit, R. and P. J. H. Schoemaker, 1993, "Strategic assets and organizational rent". Strategic Management Journal, 14: 33-46.

Angwin, D., S. Paroutis and S. Mitson, 2009, "Connecting up strategy: Are senior strategy directors (SSDs) a missing link?". California Management Review, , 51: 74-94.

Argote, L. and P. Ingram, 2000, "Knowledge transfer: A basis for competitive advantage in firms". Organizational Behavior and Human Decision Processes, 82: 150-169.

Baden-Fuller, C. and S. G. Winter, 2005, "Replicating Organizational Knowledge". Working Paper \#0515, Papers on Economics and Evolution, Max-Planck-Institute of Economics1-40.

Balogun, J. and G. Johnson, 2004, "Organizational restructuring and middle manager sensemaking". Academy of Management Journal, 47: 523-549.

Balogun, J. and G. Johnson, 2005, "From intended strategies to unintended outcomes: The impact of change recipient sensemaking". Organization Studies, 26: 1573-1601.

Bamberger, P., 2008, "Beyond Contextualization: Using Context Theories to Narrow the MicroMacro Gap in Management Research". The Academy of Management Journal, 51: 839-846.

Bartunek, J. M., P. G. FosterFishman and C. B. Keys, 1996, "Using collaborative advocacy to foster intergroup cooperation: A joint insider-outsider investigation". Human Relations, 49: 701-733.

Bechky, B. A., 2003, "Sharing meaning across occupational communities: The transformation of understanding on a production floor". Organization Science, 14: 312-330.

Belmondo, C. and C. Sargis-Roussel, 2015, "Negotiatting Language, Meaning and Intention: Strategy Infrastructure as the Outcome of Using a Strategy Tool through Transforming Strategy Objects". British Journal of Management, 26: S90-S104.

Buergi, P., C. D. Jacobs and J. Roos, 2005, "From metaphor to practice in the crafting of strategy". Journal of Management Inquiry, 14: 78-94.

Carlile, P. R., 2002, "A pragmatic view of knowledge and boundaries: Boundary objects in new product development". Organization Science, 13: 442-455.

Carlile, P. R., 2004, "Transferring, translating, and transforming: An integrative framework for managing knowledge across boundaries". Organization Science, 15: 555-568.

Collins, H. M., 2001, "Tacit knowledge, trust and the Q of Sapphire". Social Studies of Science, 31: 71-85.

D'Adderio, L., 2001, "Crafting the virtual prototype: how firms integrate knowledge and capabilities across organisational boundaries". Research Policy, 30: 1409-1424.

D'Adderio, L., 2003, "Configuring software, reconfiguring memories: the influence of integrated systems on the reproduction of knowledge and routines". Industrial \& Corporate Change, 12: 321-350.

D'Adderio, L., 2008, "The performativity of routines: Theorising the influence of artefacts and distributed agencies on routines dynamics". Research Policy, 37: 769-789.

Dameron, S., J. K. Le and C. LeBaron, 2015, "Materializing Strategy and Strategizing Material: Why Matter Matters". British Journal of Management, 26: S1-S12.

Davies, M. A. P., W. Lassar, C. Manolis, M. Prince and R. D. Winsor, 2011, "A model of trust and compliance in franchise relationships". Journal of Business Venturing, 26: 321-340.

Demir, R., 2015, "Strategy Activity as Bundled Affordances". British Journal of Management, 26: S125-S141.

Easterby-Smith, M., R. Thorpe and P. Jackson, 2008, Management research (3rd ed.). London: SAGE.

Eisenhardt, K. M. and F. M. Santos, 2002, "Knowledge-Based View: A New Theory of Strategy". In A. Pettigrew, H. Thomas, \& R. Whittington (Eds.), Handbook of Strategy \& Management: 139-164. Los Angeles: Sage.

El Akremi, A., M. K. and R. Perrigot, 2011, "Opportunistic behaviors in franchise chains: the role of cohesion among franchisees". Strategic Management Journal, 32: 930-948. 
Fauré, B. and L. Rouleau, 2011, "The strategic competenceof accountants and middle managers in budget making". Accounting, Organization and Society, 36: 167-182.

Feldman, M. S. and B. T. Pentland, 2003, "Reconceptualizing organizational routines as a source of flexibility and change". Administrative Science Quarterly, 48: 94-118.

Frery, F., 2006, "The fundamentals of strategy". Mit Sloan Management Review, 48: 71-75.

Friesl, M. and J. Larty, 2013, "Replication of Routines in Organizations: Existing Literature and New Perspectives". International Journal of Management Reviews, 15: 106-122.

Giddens, A., 1984, The constitution of society: Outline of the theory of structuration. Cambridge Cambridgeshire: Polity Press.

Golsorkhi, D., L. Rouleau, D. Seidl and E. Vaara, 2011, "Introduction: What is Strategy as Practice?". In D. Golsorkhi, L. Rouleau, D. Seidl, \& E. Vaara (Eds.), Cambridge Handbook of Strategy as Practice: 1-20. Cambridge: Cambridge University Press.

Güttel, W. H., S. W. Konlechner, B. Müller, J. K. Trede and M. Lehrer, 2012, "Facilitating Ambidexterity in Replicator Organizations: Artifacts in Their Role as Routine-Recreators". Schmalenbach Business Review, 64: 187-203.

Helfat, C. E. and M. A. Peteraf, 2003, "The dynamic resource-based view: Capability lifecycles". Strategic Management Journal, 24: 997-1010.

Heracleous, L. and C. Jacobs, 2011, Crafting strategy: embodied metaphors in practice. Cambridge: Cambridge University Press.

Heracleous, L. and C. D. Jacobs, 2008, "Understanding Organizations through Embodied Metaphors". Organization Studies, 29: 45-78.

Jarzabkowski, P., J. Balogun and D. Seidl, 2007, "Strategizing: The challenges of a practice perspective". Human Relations, 60: 5-27.

Jarzabkowski, P. and T. Pinch, 2013, "Sociomateriality is 'the New Black': accomplishing repurposing, reinscripting and repairing in context". M@n@gement, 16: 579-592.

Jarzabkowski, P., P. Spee and M. Smets, 2013, "Material artifacts: Practices for doing strategy with stuff". European Management Journal, 31: 41-54.

Jensen, R. J. and G. Szulanski, 2007, "Template use and the effectiveness of knowledge transfer". Management Science, 53: 1716-1730.

Johnson, G., L. Melin and R. Whittington, 2003, "Micro strategy and strategizing: Towards an activity-based view". Journal of Management Studies, 40: 3-22.

Jonsson, A. and N. J. Foss, 2011, "International expansion through flexible replication: Learning from the international experience of IKEA". Journal of International Business Studies, 42: 1079-1102.

Kaplan, S., 2011, "Strategy and PowerPoint: An Inquiry into the Epistemic Culture and Machinery of Strategy Making". Organization Science, 22: 320-346.

Ketokivi, M. and S. Mantere, 2010, "TWO STRATEGIES FOR INDUCTIVE REASONING IN ORGANIZATIONAL RESEARCH". Academy of Management Review, 35: 315-333.

King, A. W. and C. P. Zeithaml, 2001, "Competencies and firm performance: Examining the causal ambiguity paradox". Strategic Management Journal, 22: 75-99.

Knorr-Cetina, K. D., 2001, "Objectual practice.". In T. Schatzki, K. D. Knorr Cetina, \& E. Savigny (Eds.), The Practice Turn in Contemporary Theory: 175-188. London: Routledge.

Leonardi, P. M., 2015, "Materializing Strategy: The Blurry Line between Strategy Formulation and Strategy Implementation". British Journal of Management, 26: S17-S21.

Leonardi, P. M. and S. R. Barley, 2010, "What's under construction here? Social action, materiality, and Power in Constructivist Studies of Technology and Organizing". Academy of Management Annals, 4: 1-51.

Lervik, J. E., B. W. Hennestad, R. P. Amdam, R. Lunnan and S. M. Nilsen, 2005, "Implementing human resource development best practices: Replication or re-creation?". Human Resource Development International, 8: 345-360.

Lippmann, S. and R. Rumelt, 1982, "Uncertain imitability: An analysis of interfirm differences in efficiency under competition". Bell Journal of Economics, 13: 418-438.

McDonald, C., 1998, "The Evolution of Intel's Copy Exactly Policy". Intel Technology Journal1-6.

McQueen, R. and C. Knussen, 2002, Research methods for social science. An introduction. Harlow: Prentice Hall. 
Meyer, J. W. and B. Rowan, 1977, "Institutionalized organizations: Formal-structure as myth and ceremony". American Journal of Sociology, 83: 340-363.

Miettinen, R. and J. Virkkunen, 2005, "Epistemic Objects, Artefacts and Organizational Change". Organization, 12: 437-456.

Miles, M. B. and A. M. Huberman, 1984, Qualitative data analysis. A sourcebook of new methods. London: Sage.

Mintzberg, H., 2000, The rise and fall of strategic planning. London: Prentice Hall.

Nelson, R. R. and S. G. Winter, 1982, An evolutionary theory of economic change. Cambridge, Mass.: Belknap Press of Harvard University Press.

Nemeth, C., K. Brown and J. Rogers, 2001, "Devil's advocate versus authentic dissent: Stimulating quality and quantity". European Journal of Social Psychology, 31: 707-720.

Nightingale, P., 1998, "A cognitive model of innovation". Research Policy, 27: 689 - 709.

Nonaka, I. and H. Takeuchi, 1995, The knowledge creating company - How Japanese companies create the dynamics of innovation. New York, Oxford: Oxford University Press.

Orlikowski, W. J., 2007, "Sociomaterial Practices: Exploring Technology at Work". Organization Studies, 28: 1435-1448.

Orlikowski, W. J. and S. V. Scott, 2008, "Sociomateriality: Challenging the Seperation of Technology, Work and Organization". The Academy of Management Annals, 2: 433-474.

Paroutis, S., L. A. Franco and T. Papadopoulos, 2015, "Visual Interactions with Strategy Tools: Producing Strategic Knowledge in Workshops". British Journal of Management, 26: S48S66.

Paswan, A. K. and C. M. Wittmann, 2009, "Knowledge management and franchise systems". Industrial Marketing Management, 38: 173-180.

Pentland, B., 2003, "Sequential variety in work processes". Organization Science, 14: 528-540.

Pentland, B. T. and M. S. Feldman, 2005, "Organizational routines as a unit of analysis". Industrial and Corporate Change, 14: 793-815.

Pizanti, I. and M. Lerner, 2003, "Examining control and autonomy in the franchisor-franchisee relationship". International Small Business Journal, 21: 131-159.

Polanyi, M., 1964, Personal Knowledge. New York: Harper and Row.

Reckwitz, A., 2002, "Toward a theory of social practices: A development in culturalist theorizing". European Journal of Social Theory, 5: 243-263.

Reynaud, B., 2005, "The void at the heart of rules: routines in the context of rule-following. The case of the Paris Metro Workshop". Industrial and Corporate Change, 14: 847-871.

Rouleau, L., 2005, "Micro-Practices of Strategic Sensemaking and Sensegiving: How Middle Managers Interpret and Sell Change Every Day". Journal of Management Studies, 42: 14131441.

Spee, A. P. and P. Jarzabkowski. 2009. Strategy tools as boundary objects, Strategic Organization, Vol. 7: 223-232.

Spee, A. P. and P. Jarzabkowski, 2011, "Strategic planning as communicative process". Organization Studies, 32: 1217-1245.

Suddaby, R., 2006, "From the editors: What grounded theory is not". Academy of Management Journal, 49: 633-642.

Szulanski, G., 1996, "Exploring internal stickiness: Impediments to the transfer of best practice within the firm". Strategic Management Journal, 17: 27-43.

Szulanski, G., 2000, "The process of knowledge transfer: A diachronic analysis of stickiness". Organizational Behavior and Human Decision Processes, 82: 9-27.

Szulanski, G. and R. J. Jensen, 2004, "Overcoming stickiness: An empirical investigation of the role of the template in the replication of organizational routines". Managerial and Decision Economics, 25: 347-363.

Szulanski, G. and R. J. Jensen, 2008, "Growing through copying: The negative consequences of innovation on franchise network growth". Research Policy, 37: 1732-1741.

Szulanski, G., D. Ringov and R. J. Jensen, 2016, "Overcoming stickiness: How the timing of knowledge transfer methods affects trasfer difficulty". Organization Science, fc.

Vaara, E. and R. Whittington, 2012, "Strategy-as-Practice: Taking Social Practices Seriously". The Academy of Management Annals1-52. 
Werle, F. and D. Seidl, 2015, "The layered materiality of strategizing: Epistemic objects and the interplay between material artefacts in the exploration of strategic topics". British Journal of Management, 26: S67-S89.

Whittington, R., 2006, "Completing the Practice Turn in Strategy Research". Organization Studies, 27: 613-634.

Whittington, R., 2007, "Strategy practice and strategy process: family differences and the sociological eye". Organization Studies, 28: 1575-1586.

Whittington, R., 2015, "The Massification of Strategy". British Journal of Management, 26: S13S16.

Williams, M., 2000, "Interpretivism and Generalisation". Sociology, 34: 209-224.

Winter, S. G., 1995, "Four Rs of profitability: rents, resources, routines and replication". In C. Montgomery (Ed.), Resource-Based and Evolutionary Theories of the Firm: Towards a Synthesis: 147-178. Boston: Kluwer Academic Publishers.

Winter, S. G. and G. Szulanski, 2001, "Replication as strategy". Organization Science, 12: 730-743.

Winter, S. G., G. Szulanski, D. Ringov and R. J. Jensen, 2012, "Reproducing Knowledge: Inaccurate Replication and Failure in Franchise Organizations". Organization Science, 23: 672-685.

Wirtz, B. W., A. Mathieu and O. Schilke, 2007, "Strategy in high-velocity environments". Long Range Planning, 40: 295-313.

Yin, R. K., 2009, Case study research: Design and methods (4th ed.). Los Angeles: Sage Publications.

Zander, U. and B. Kogut, 1995, "Knowledge and the Speed of the Transfer and Imitation of Organizational Capabilities - an Empirical-Test". Organization Science, 6: 76-92.

Zenger, T. R. and S. G. Lazzarini, 2004, "Overcoming Stickiness: An Empirical Investigation of the Role of the Template in the Replication of Organizational Routines". Managerial \& Decision Economics, 25: 347-363.

Zollo, M. and S. G. Winter, 2002, "Deliberate learning and the evolution of dynamic capabilities". Organization Science, 13: 339-351. 